\title{
School Health Services Project on Personal Hygiene among School Children of Age 12-15 in Underprivileged Community in Karachi
}

\author{
Shahzad Bashir and Sarfraz Masih* \\ Institute of Nursing Dow University of Health Sciences Karachi, Pakistan
}

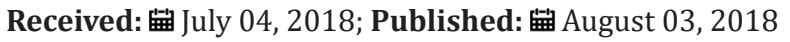

*Corresponding author: Sarfraz Masih, Institute of Nursing Dow University of Health Sciences Karachi, Pakistan

Abbreviations: MDG: Millennium Development Goal; CD: Communicable Diseases; DM: Diabetes Mellitus

\section{Introduction}

Hygiene is one of the pivotal parts of life. It is very necessary for living a healthy life style. However, hygiene is extensive term of science which indentures with promotion and protection of health, eventually, preceding the individuals' healthy behavior. In fact, the word hygiene is derived from the Greek word "Hygieia" which means the spirit of health purity, sanitation and cleanliness [1]. Therefore, personal hygiene considered in broad category of health, such as face, hand, oral, hair, nail and feet hygiene. However, it does vary from person to person to follow these personal hygienic practices but its depend upon their family norms, culture and society etc [2]. It is observed that poor hygienic conditions and practices have increased the burden of communicable diseases among developed and under developing countries including Pakistan [1] (Figures 1-5). Most of the health related problems affecting school going children are due to the improper personal hygienic practices. Such health related problems can be controlled and prevented by promoting good personal hygiene through awareness and proper health education strategies by school teachers and administrative staff.

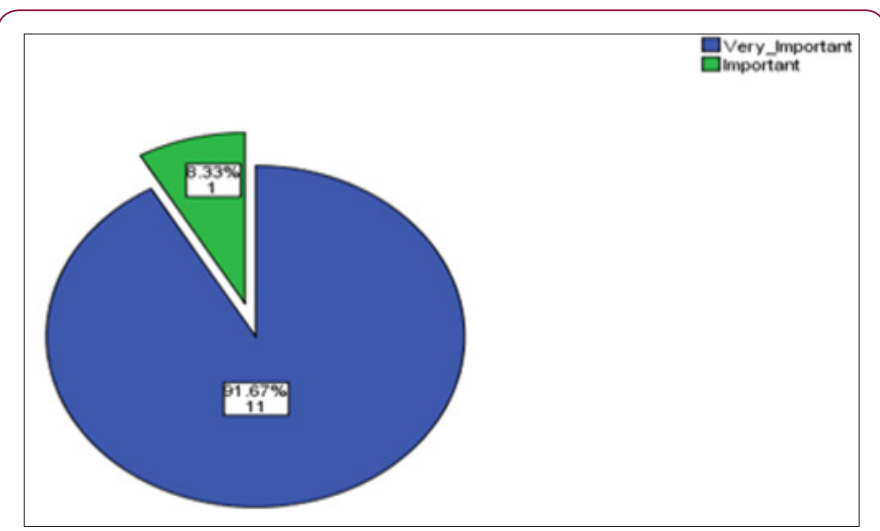

Figure 1: Importance of oral hygiene for children.

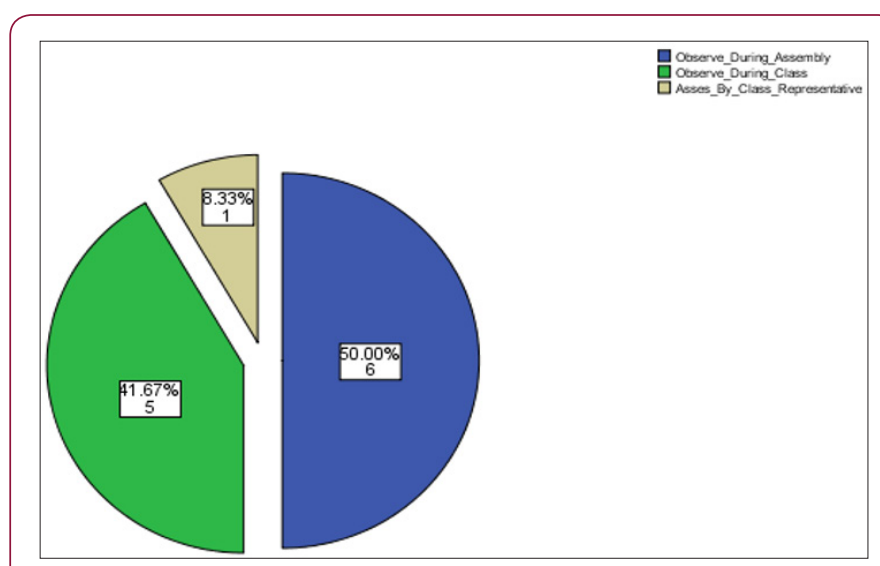

Figure 2: How do you asses children for oral hygiene.

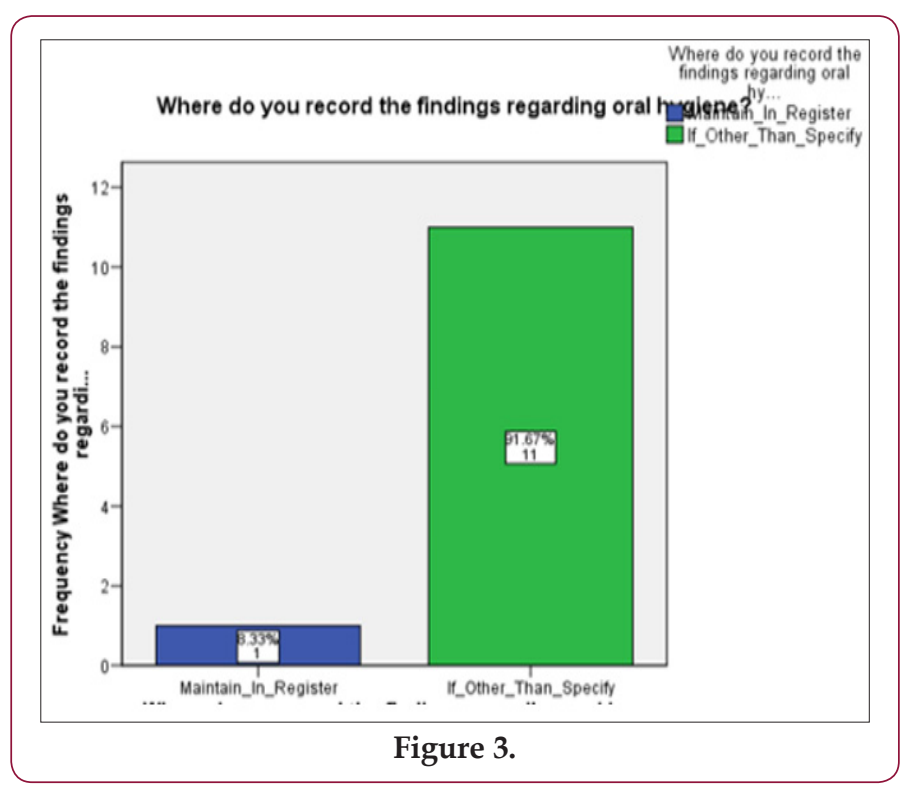



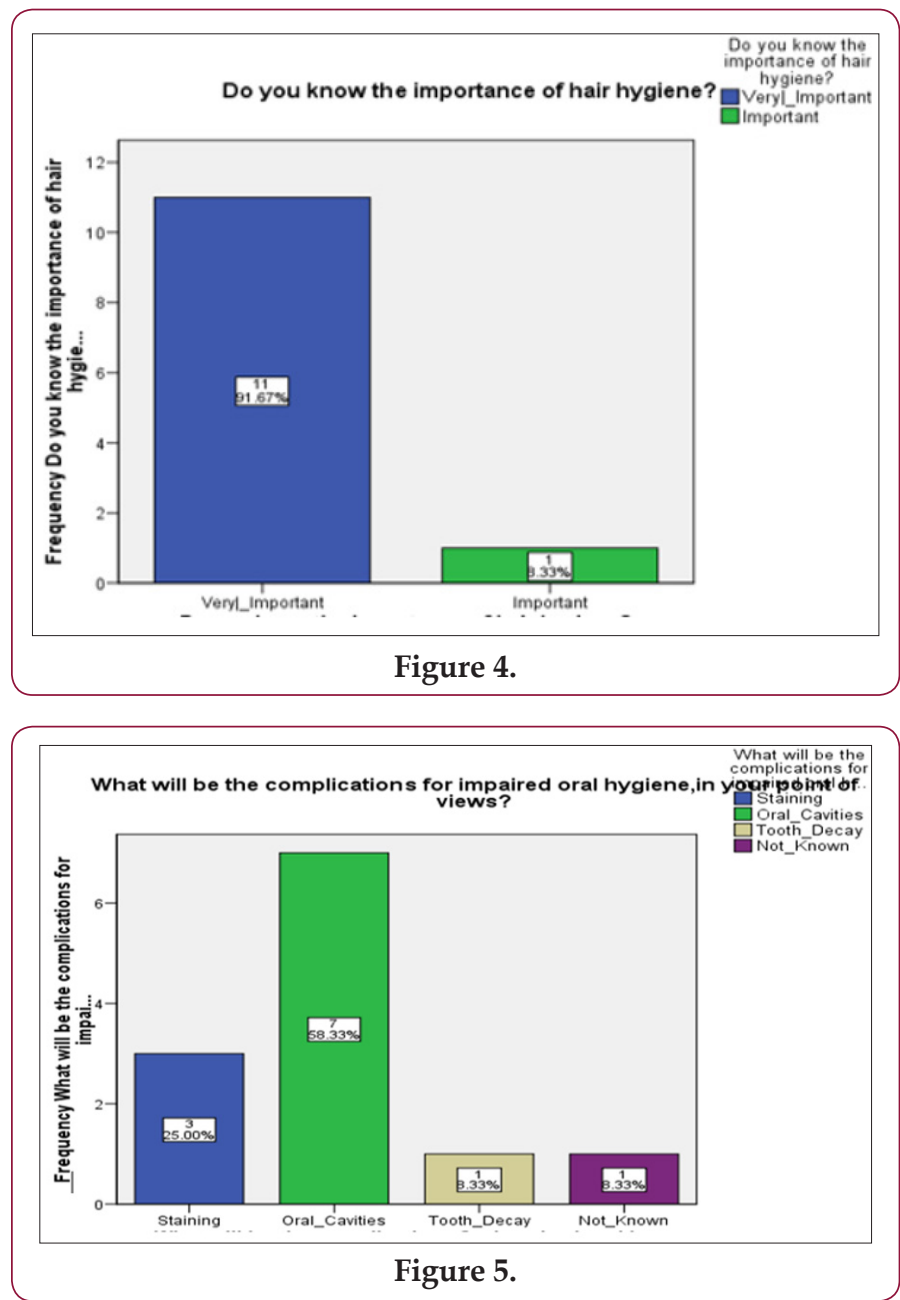

Indeed, proper personal hygiene practices are one of the best approaches to control communicable diseases which will be mainly spread through water, food, personal contacts and microorganisms such as viruses, bacteria, and protozoa etc [1]. Globally, the Millennium Development Goal (MDG) Six (6) has raised the agenda regarding the issues of hygiene, water, and sanitation [1]. Indeed, 2.5 billion people living with poor personal hygiene practices around the globe [3]. Furthermore, majority of the diseases can be prevented if, school going children developed good personal hygiene habits which will further improve their health throughout the lifetime. It has been observed that the burden of personal hygiene especially, oral hygiene is prevailed among under developing countries instead of developed [4]. However, it consistently increased the burden of communicable diseases (CDs) among school children. School going children are susceptible to neglect the primary personal hygienic practices due to lack of knowledge [5].

Poor personal hygiene especially teeth brushing plays a major role to developed tooth decay among school going children which will ultimately affect on their development. It is estimated that dental caries affected $60-90 \%$ of school going children around the globe [6]. Moreover, early healthy personal hygiene habits in the beginning among school going children help to transition into hygiene routines in adulthood. If it will be untreated, it will progressively and cumulatively become more multifaceted over time, and will affect the children's quality of life i.e., will change eating and chewing habits [7] (Figures 6-10). The positive aspects of personal hygiene cannot be achieved without the assessing in real situation. In Pakistani context, school health services are not in common practice, particularly in government schools in slum areas. In lieu of that, an under privileged community was approached for understanding the school health services. The main objective of this project was to identify health issues and conduct project in school health services.
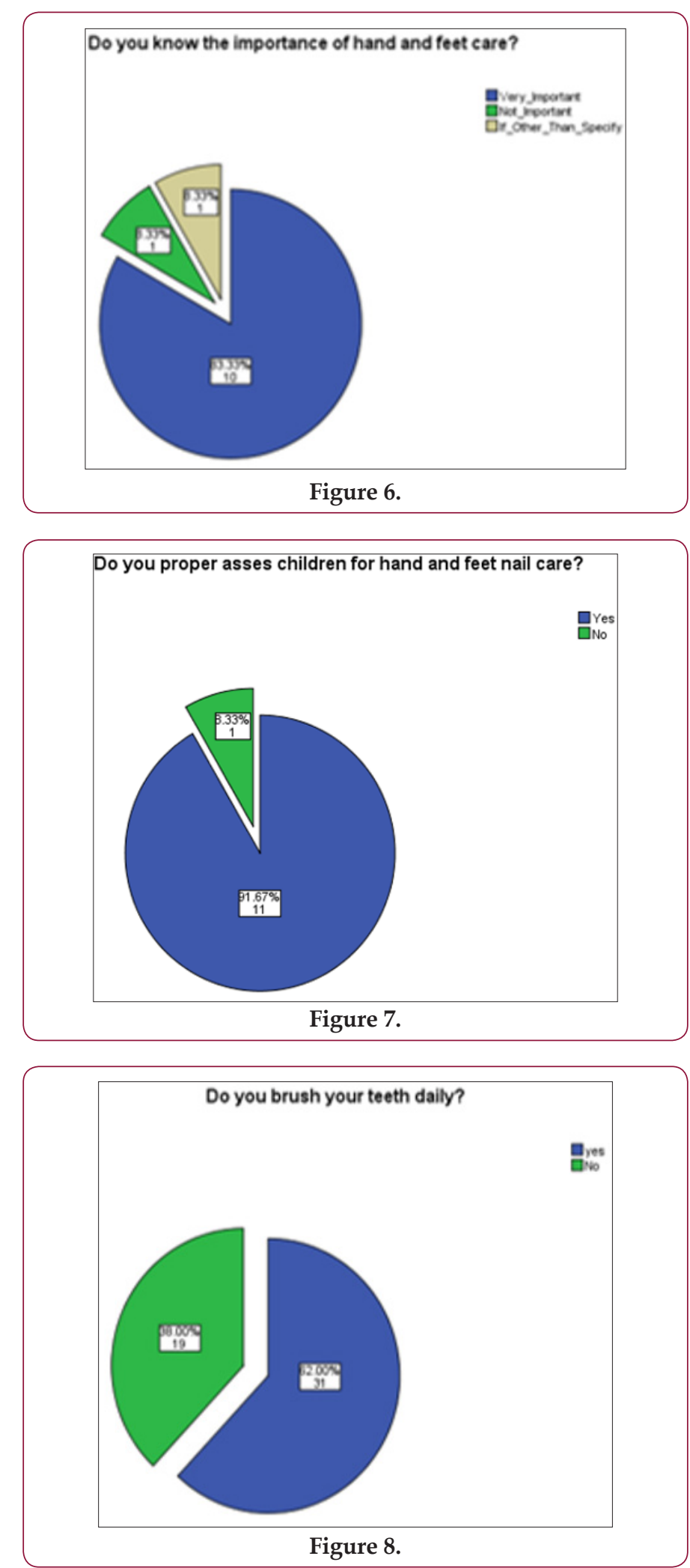


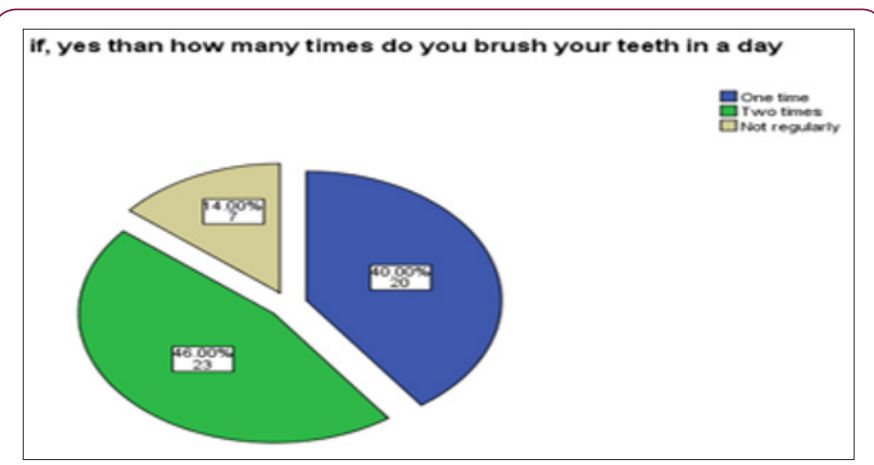

Figure 9.

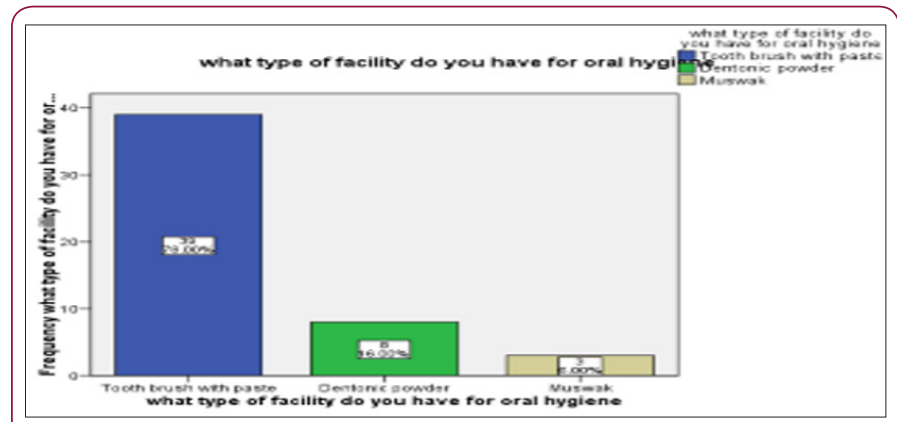

Figure 10.

\section{Assessment}

For identification of the health issue for research project in school health services, assessment was initial step taken. Assessment is the first and critical phase of gathering information for the research project in systematic way [8]. Cross sectional approach was carried out for three (3) weeks for assessment through observations inside the school and assessing the families of that community through convenient sampling in November 2015. During observation in the school, broad range of health issues among children were identified consisting lice infestations, dental carries, tooth decayed, long nails with full of mud and even majority of children walking with bear foot. During families' assessment, sixteen families were approached. Major health problems found were,
b) Child abuse and neglect,
c) Domestic violence,
d) drug abuse,
e) HIV/AIDS, (DM),
g) Inadequate medical services,
h) Lack of affordable houses,
i) Scabies,
j) Diarrhea, and
k) Poverty.

a) Inadequate assess to clean drinking water,

f) Undiagnosed hypertension (HTN) and Diabetes Mellitus
Based on assessment of the school health and families health issues, it was prioritized the need of the community to conduct project on 'Personal Hygiene in school health services'. For further in-depth assessment of personal hygiene in school health services, data were collected through structured questionnaires from 12 teachers and 50 school children of $6^{\text {th }}$ and $7^{\text {th }}$ class about knowledge and attitude of regarding personal hygiene (oral, nails, hairs and foot care) of school children. Teachers and school children were approached after the written permission of the principal of that school. Also verbal consent from the teachers and school children were taken prior to data collection. The study participants were informed about the project, its purpose and about the confidentiality issue.

\section{Results of In-depth Assessment of Personal Hygiene in School Health Services from Teachers}

Data were analyzed by using SPSS 19 version. Out of 12 teachers 07 (58.33\%) were males and 05 (41.67\%) were females. Majority of the teachers (41.67\%), were of age between $40-45$, and $11(91.67 \%)$ have completed teachers training with professional course, 9 (75\%) had master's Degree in education. Out of 12 patients $11(91.67 \%)$ considered as oral hygiene for children is very important, and $1(8.33 \%)$ replied that oral hygiene for children is important. Around $6(50 \%)$ teachers assessed children generally for oral hygiene during assembly, 5 (41.67\%) in class, and 1 (8.33\%) assessed by class representative. In regard to the maintenance of personal health record of the students, 11 (91.67\%) replied that they do not know where they maintained the record. Majority of the teachers, 11 (91.67\%), agreed that importance of hair hygiene is very important, 7 (58.33\%) agreed that oral cavities are one of the complications of oral hygiene. Furthermore, the importance of hand and feet care, was rated by $10(83.33 \%)$ teachers. Moreover, while assessment of hand and feet care out of 12, 11 (91.67\%) were agreed yes, they assess children related to hand and feet care, whereas 1 (8.33\%) were agreed no (Figure; Do you assess children for hand and feet care). Brief detail of the results of assessment about the personal hygiene among the school children is also illustrated in pie and bar charts:

\section{Results of In-depth Assessment of Personal Hygiene in School Health Services from Students}

Out of 50 students 22 were males and 28 were females. Majority of the students, $31(62 \%)$ respond that they brush their teeth daily, and response of 19 (38\%), was that they are not used to brush their teeth on daily basis. Only, 23 (46\%) students brush teeth once a time. In respect of facility for oral hygiene, 39 (78\%) children responded that they use tooth brush with paste, whereas $3(6 \%)$ respond used of muswak (use of piece of tree branch). Around 37 (80.43\%) responded that they ate junk food during school timings. Moreover, 34 (68\%) children answered that they did not visit dentist or General physician for oral checkup. Most of the participants 38 (76\%) (Figures 11-14). responded that they used shampoo for hair hygiene, 20 (40.82\%) children replied that they do not know the complications of improper of hairs hygiene. As well, 24 (48\%) children answered that they did not know the 
importance of fingers and toenails care. Brief detail of the results of assessment about the personal hygiene among the school children is mentioned in pie and bar charts: In view of the results of the assessment, planning was next step followed.
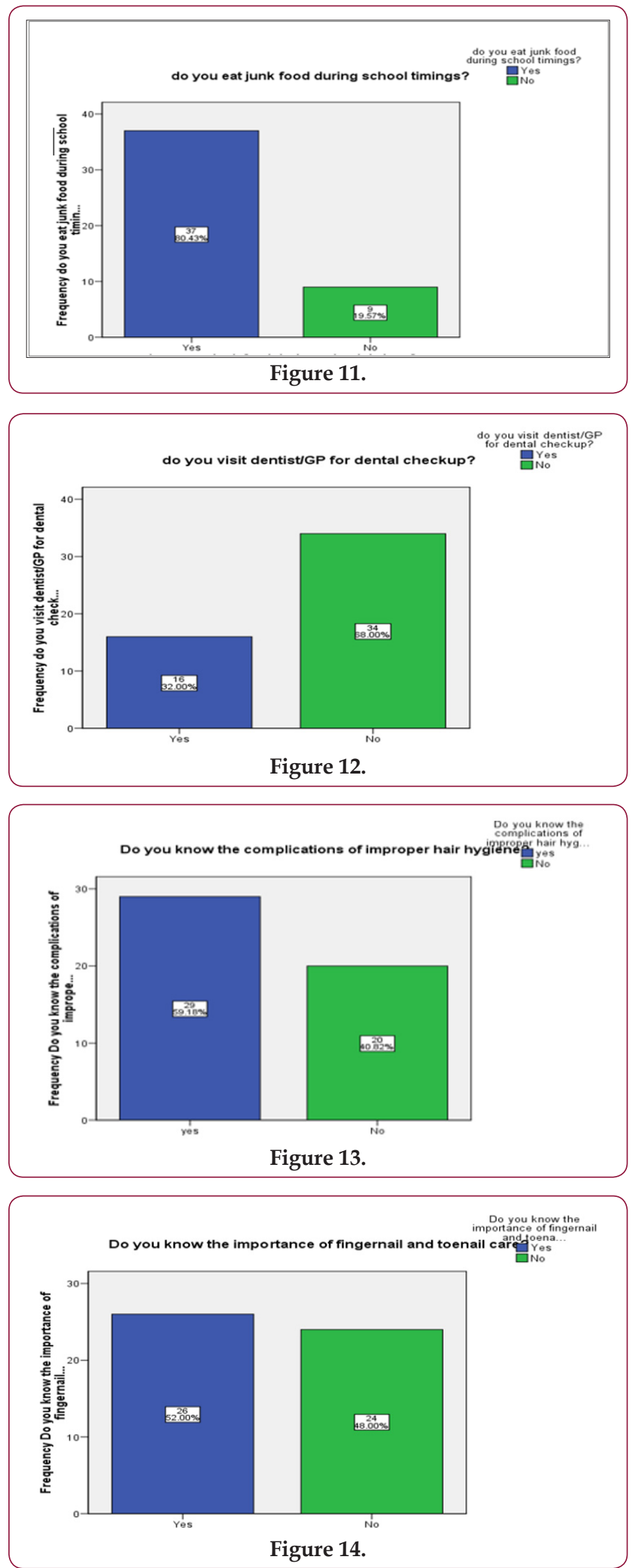

\section{Planning}

For next step, planning was carried out with discussion of the headmaster of that school, course facilitator and group members for conducting the project in two sessions for implementation. First session was to conduct teaching session; whereas second session was to screen the oral hygiene of all school children.

\section{Project Objectives for Implementation}

Project objectives for implementation were to:

a) Provide awareness regarding health issues and its complications especially oral, hair, nail, and feet care.

b) Discuss the importance of healthy life style such as daily oral hygiene, hair care and as well as foot care.

c) Develop initial framework for school health services to protect children within the school premises by identification of carelessness among children related to oral, hairs as well as feet care hygiene.

d) Screen the children for oral hygiene by dentist team members.

\section{Implementation}

For teaching session, flyer was distributed among the school children and teachers. A teaching session was conducted in December 2015 by group of MSN students through lecture, multimedia presentations, charts, models, demonstration and Panaflex. The teaching session focused on oral hygiene, nail care, hair care, and feet care. Oral hygiene was emphasized on teeth brushing techniques to control dental carries and cavities. However, prepared brochure was delivered to students on it oral teeth brush procedure and its technique mentioned. Furthermore, for effectiveness of oral teaching session, the demonstration on teeth model was done by one of student. On hair hygiene, it was more emphasized on how to comb hairs, to control pediculosis and lice infestation. Moreover, antilice shampoos were distributed among school children. In nail care, the importance of nails care and its diseases was highlighted. Furthermore, the ignorance of nail care was also explained to school children through photographic charts. This session was concluded the demonstration of nails trimming by one of the school student of $6^{\text {th }}$ class.

After that nail cutters were also given to some of school children to keep as gratitude of listening and learning. In feet care, the highlighted diseased was discussed in details, and discussed the procedure of feet care with the help of foot model and different charts. One register was prepared for writing the assessment of personal hygiene of school children and handed to headmaster of the school. After finishing the implemented teaching sessions, the refreshment was served among school children, staff and teachers. Second session was carried out by arranging dental camp for oral screening in December, 2015. School children of other classes along class $6^{\text {th }}$ and $7^{\text {th }}$ were screened by dentist team members. For encouragement, dental kit including tooth brush, floss, and tooth paste were distributed among the school children and teachers. 


\section{Evaluation}

It was planned to revisit after four weeks after implementation phase to assess or evaluate the sustainability of the project. It is observed and also got information after four weeks among BMB government high school children especially target group which was class $6^{\text {th }}$ and $7^{\text {th }}$. The observation and information were follows:

a) Majority of $6^{\text {th }}$ and $7^{\text {th }}$ class School children verbalized that, they brushes their teeth two times daily with recommended times and techniques.

b) They also follow the hair hygiene instructions as well.

c) On observation nails was trimmed properly and smoothly once in a week as recommended instructions.

d) It was observed that the target group of $6^{\text {th }}$ and $7^{\text {th }}$ class was wearing school shoes according to weather, with proper size.

\section{Recommendations Regarding Personal Hygiene for Faculty and School Children}

a) Personal hygiene is the core of the health, especially oral, hair, nail and feet care.

b) Personal hygiene will help the school children to keep them healthy and smart and providing them a platform for successful development in their career step by step.

c) School children must follow the guidelines and technique regarding personal hygiene and also follows the rules and regulations of the school.

d) School children should participate in all the activities which keep them healthy, i.e. pity activities, general screening during assembly.

e) School children should quit off all the unhealthy activities such as eating junk food, challia chewing etc., which proceeds to dental carries and cavities. While about hair care they should shower daily and comb hairs, to control pediculosis and lice infestation.

f) Furthermore, regarding Nail care, it is very important to trimmed nails according to need.

g) Additionally, feet are the most neglected part of our body and if we not maintain its hygiene it will proceeds to further complications such as in growing toe nail etc. h) Ongoing assessment should be done by the Class representative of each class under the supervision of faculty.

i) Faculty of the school should be well trained and skillful regarding the implementation of personal hygiene.

j) Professional Communication skills should be used within class colleagues, faculty members, seniors and also with students.

\section{Acknowledgement}

Facilitation by Ms. Shehla Naeem Zafar, Associate Professor, Institute of Nursing, Dow University of Health Sciences, during project duration, and support from fellow colleagues (Muhammad Shahid, and Alic, Faryal Victoria) during MSN studies, is acknowledged.

\section{References}

1. Motakpalli K, Indu AS, Sirwar SB, Jayaalakshmi K, Bendigeri N, et al. (2013) A study on health hygiene among school children in rural field practice area of Ajims Mangalore in Karnataka: India. International Journal of Bioassays 2(10): 1407-1410.

2. Hassan BAR (2012) Importance of Personal Hygiene. Pharmaceut Anal Acta 3(8): 125.

3. Shrestha A, Angolkar M (2014) Impact of Health Education on the Knowledge and Practice Regarding Personal Hygiene among Primary School Children in Urban Area of Karnataka, India. IOSR Journal of Dental and Medical Sciences 3(4): 38-44.

4. Okemwa K, Gatongi P, Rotich J (2010) The oral health knowledge and hygiene practices among primary school children aged 5-17 years in a rural area of Uasin Gishu District, Kenya 7(2): 187-190.

5. Ghanim M, Dash N, Abdullah B, Issa H, Albarazi R, et al. (2016) Knowledge and Practice of Personal Hygiene among Primary School Students in Sharjah-UAE. Journal of Health Science 2016(65): 67-73.

6. Thapa P, Aryal K, Dhimal M, Mehata S, Pokhrel A, et al. (2015) Oral Health Condition of School Children in Nawalparasi District, Nepal. Journal of Nepal Health Research Council 13(29): 7-13.

7. Jürgensen N, Petersen P (2013) Promoting oral health of children through schools-Results from a WHO global survey 2012. Community Dent Health 30 (4): 204-218.

8. Bennett RE (2011) Formative assessment: A critical review. Assessment in Education: Principles, Policy \& Practice 18(1): 5-25. 


\section{ISSN: 2574-1241}

DOI: 10.26717/BJSTR.2018.07.001531

Sarfraz Masih. Biomed J Sci \& Tech Res

(c) This work is licensed under Creative

Submission Link: https://biomedres.us/submit-manuscript.php

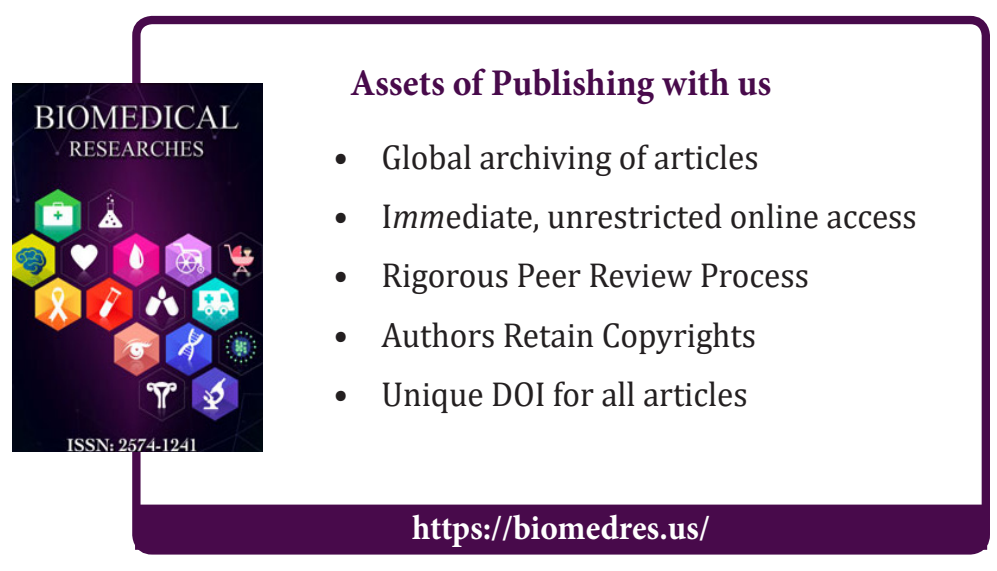

